\title{
Optimal Coverage for Incompletely Reliable Insurance ${ }^{1}$
}

\author{
Olivier MAHUL \\ Capital and Risk Markets, Financial Vice Presidency, The World Bank \\ Brian D. WRIGHT \\ Department of Agricultural and Resource Economics, University of California, Berkeley
}

Revised version: July 2006

(Forthcoming, Economics Letters)

Corresponding author:

Olivier Mahul

The World Bank

1818 H Street NW

Washington DC, 20433

Phone: (202) 458-8955.

Fax: (202) 522-7105.

E-mail: omahul@worldbank.org

\footnotetext{
${ }^{1}$ The authors wish to thank an anonymous referee for helpful comments.
} 


\title{
Optimal Coverage for Incompletely Reliable Insurance
}

\begin{abstract}
Optimal actuarially fair coverage of insurance subject to default risk is less or more than full, depending upon the relation between the recovery rate under default and a positive trigger level that is independent of the insured's risk preference.
\end{abstract}

JEL subject codes: D81, G22

Keywords: default risk, incomplete markets, insurance contract design, partial payment. 


\section{Introduction}

The literature of the demand for insurance in the tradition of Mossin (1968) relies on the implicit assumption that insurance policies are fully performing, i.e., insurers always pay valid claims in full. A notable exception is Doherty and Schlesinger (1990) who address the effect of risk of nonperformance on rational insurance purchases. They show that if default, when it occurs, is always total, less-than-full insurance coverage is always purchased at a fair price. Surprisingly, since this starting point for analyzing the demand for insurance that is unreliable due to default risk, very few papers have investigated this area (e.g., Hau 1999, Mahul and Wright 2004).

In particular, a frequently observed form of nonperformance consists of less than total default, involving behavior (delay, undervaluation of losses, litigation with settlement) that effectively gives partial indemnification, rather than none at all. This paper examines the implications of partial indemnification under nonperformance in the three-state model proposed by Doherty and Schlesinger (1990). We show that there exists a trigger recovery rate under non-performance such that, when sold at a fair price, the optimal unreliable insurance contract displays less-than-full (full, more-than-full) coverage as

long as the recovery rate is lower than (equal to, higher than) this trigger rate. We also explain why, under risk of partial default, no monotonic relationship exists between risk aversion and the level of unreliable insurance coverage.

\section{The model}

The consumer is assumed to be atomistic and strictly risk averse with von NeumannMorgenstern utility of wealth represented by the twice differentiable function $u$, with 
$u^{\prime}>0$ and $u^{\prime \prime}<0$. She is endowed with non-random initial wealth $w_{0}$. In the three-state model proposed by Doherty and Schlesinger (1990), she suffers a loss of $L>0$ or zero with probabilities $p \in(0,1)$ and $(1-p)$, respectively. Conditional on the occurrence of the loss, the insurer gives total indemnification or partial indemnification with probability $q \in[0,1]$ and $(1-q)$, respectively. The recovery rate under nonperformance is $t \in[0,1]$.

The consumer is able to purchase unreliable insurance by specifying a proportion $\alpha$ of the loss that is to be insured, $\alpha \geq 0$. This insurance policy is assumed to be sold at an actuarially fair price. The expected utility of her final wealth is

$$
U \equiv(1-p) u\left(w_{1}\right)+p q u\left(w_{2}\right)+p(1-q) u\left(w_{3}\right),
$$

where $w_{1}=w_{0}-P, w_{2}=w_{0}-P-L+\alpha L, w_{3}=w_{0}-P-L+t \alpha L$ and, under fair

insurance, $P=\alpha L p[q+t(1-q)]$.

First consider some obvious cases. When the recovery rate is one, the standard model applies (Mossin 1968). The case where the probability of default is one and the recovery rate is zero means that no insurance is available. Finally, when the probability of default is one and the recovery rate is strictly positive, the standard model applies where the effective rate of insurance is $t \alpha$. If, for example, $t=0.5$, then the consumer would buy twice the nominal "full coverage" and be fully indemnified should a loss occur. To focus on more interesting cases, we shall assume hereafter that $q \in(0,1)$ and $t \in[0,1)$. Then the consumer is over-indemnified under full performance, and underindemnified under nonperformance.

\section{Optimal coverage under risk of partial indemnification}


The consumer's objective is to find the coverage proportion $\alpha$ that maximizes the expected utility of her final wealth expressed in equation (1). The first-order condition of this maximization problem is

$$
\frac{d U}{d \alpha}=p L\left\{-(1-p)(q+t(1-q)) u^{\prime}\left(w_{1}\right)+q[1-p(q+t(1-q))] u^{\prime}\left(w_{2}\right)+(1-q)[t-p(q+t(1-q))] u^{\prime}\left(w_{3}\right)\right\}=0
$$

The second-order condition is satisfied under risk aversion. We evaluate $d U / d \alpha$ at full coverage under performance, $\alpha=1$. First, observe that when $\alpha=1$, we have $w_{1}=w_{2}=w_{0}-P$ and $w_{3}=w_{0}-P-L(1-t)$, with $P=L p[q+t(1-q)]$. We get

$\left.\frac{d U}{d \alpha}\right|_{\alpha=1}=p L\left\{\left[-(1-p) q-(1-p)(1-q) t+q-p q^{2}-p q(1-q) t\right] u^{\prime}\left(w_{1}\right)+(1-q)[t-p(q+t(1-q))] u^{\prime}\left(w_{3}\right)\right\}$

Denoting

$$
\hat{t} \equiv p q /(1-p(1-q)),
$$

equation (3) can be rewritten as

$$
\left.\frac{d U}{d \alpha}\right|_{\alpha=1}=L p(1-q)(1-p(1-q))[t-\hat{t}]\left[u^{\prime}\left(w_{3}\right)-u^{\prime}\left(w_{1}\right)\right]
$$

Because $w_{3}<w_{1}$ for all $t \in[0,1)$, the difference in marginal utilities in equation (5) is positive under risk aversion. This implies that the optimal coverage level $\alpha^{*}$ is lower than (equal to, higher than) one if and only if the recovery rate $t$ is lower than (equal to, higher than) $\hat{t}$, when the contract is sold at an actuarially fair price. This leads to the following proposition.

Proposition. Under risk of partial default, the optimal fair performing insurance contract displays less-than-full (full, more-than-full) coverage if and only if the recovery 
rate $t$ under partial default is lower than (equal to, higher than) a trigger level $\hat{t} \equiv p q /(1-p(1-q))$

In addition, one can show that $d U / d \alpha$ evaluated at $\alpha=0$ is positive and that $d U / d \alpha$ evaluated at $\alpha=1 / t$, with $t>0$, is negative. This implies that $t \alpha^{*}<1$, i.e., the consumer is under-indemnified in the insured loss state under default.

While a simple monotonic relationship between the level of coverage and the recovery rate does not emerge, as mentioned by Doherty and Schlesinger (1990), the Proposition shows that there exists a trigger recovery rate under (at, above) which lessthan-full (full, more-than-full) unreliable insurance coverage is optimal. This trigger level $\hat{t}$ is independent of the attitudes towards risk and of the loss. It is based only on the probability of loss $p$ and the probability of full performance $q$. It increases with both probabilities, $d \hat{t} / d p>0$ and $d \hat{t} / d q>0$. In other words, the higher the probability of loss and/or the probability of full performance, the wider the set of trigger rates in which lessthan-full insurance coverage is optimal at an actuarially fair price. Figure 1 depicts the trigger recovery rate as a function of the probability of loss and the probability of full performance. For example, when the probability of loss is 0.5 , the insured purchases lessthan-full coverage as long as the recovery rate is lower than $9 \%$ if $q=0.1,33 \%$ if $q=0.5$, and $47 \%$ if $q=0.9$.

\section{[INSERT FIGURE 1]}

This analysis includes total default risk, $t=0$, examined by Doherty and Schlesinger (1990) as a special case. Note that $t \alpha L-P=\alpha L[1-p(1-q)][\hat{t}-t]$. In the insured loss state under default, less-than-full (full, more-than-full) premium is returned to the 
policyholder if and only if the recovery rate is lower than (equal to, higher than) the trigger level $\hat{t}$. In all cases prices are actuarially fair. But a recovery rate not less than $\hat{t}$ corresponds to the "money back guarantee" case examined by Schlesinger and Schulenberg (1987). Insurance does not make the worse state even worse, since indemnification in that state exceeds the premium.

Proposition 1 can be illustrated within a mean-variance framework. Assuming actuarially fair insurance prices, the optimal unreliable insurance coverage minimizes the variance of final wealth. Doherty and Schlesinger (1990, equation ( $\left.4^{\prime}\right)$ ) show that the optimal coverage $\alpha^{*}$ is

$$
\alpha^{*}=\frac{(1-p)[(1-q) t+q]}{q+(1-q) t^{2}-p[(1-q) t+q]^{2}} .
$$

Suppose for example that $p=q=1 / 2$. When the recovery rate is equal to $1 / 5(1 / 3,1 / 2)$, the optimal insurance coverage is, from equation (6), equal to $15 / 17<1(1,12 / 11>1)$. From equation (4), the trigger recovery rate is $\hat{t}=1 / 3$. Hence, the optimal insurance coverage is lower than (equal to, higher than) one as long as the recovery rate is lower than (equal to, higher than) $\hat{t}=1 / 3$.

\section{Increased risk aversion}

How does an increase in risk aversion affect optimal unreliable insurance coverage? The wealth in the insured loss state with nonperformance can be rewritten as $w_{3}=w_{0}-P-L+t \alpha L=w_{0}-L+\alpha L[1-p(1-q)][\hat{t}-t]$. For all $t \in[0,1)$ and $q \in(0,1)$, we have 


$$
\begin{aligned}
& \frac{d w_{1}}{d \alpha}=-L p[q+t(1-q)]<0 \\
& \frac{d w_{2}}{d \alpha}=L p(1-q)\left[\frac{1-p q}{p(1-q)}-t\right]>0 \\
& \frac{d w_{3}}{d \alpha}=L[1-p(1-q)](t-\hat{t}) .
\end{aligned}
$$

Consider the case where $\hat{t}<t<1$. The wealth of the insured loss state with nonperformance is higher than the wealth of the loss state without insurance, $w_{3}>w_{0}-L$. The wealth of the insured loss state under performance is higher than the wealth of the insured no loss state because, from the Proposition, more-than-full coverage is optimal, $w_{2}>w_{1}$. The wealth of the insured loss state under default is lower than the wealth of the insured no loss state, $w_{2}>w_{1}$, because the optimal insurance coverage is less than $1 / t$. A marginal increase in the insurance coverage decreases $w_{1}$, from (7), increases $w_{2}$, from (8), and increases $w_{3}$, from (9) with $t>\hat{t}$. As depicted in Figure 2, this marginal increase in the insurance coverage is neither a mean-preserving contraction nor a mean-preserving spread (Rothschild and Stiglitz 1970). As a consequence, more risk aversion, as defined by Pratt (1964) can imply either an increase or decrease in the optimal coinsurance coverage.

\section{[INSERT FIGURE 2]}

Likewise, it can be easily shown that, when $0 \leq t<\hat{t}$, a marginal increase in the insurance coverage generates neither a mean-preserving spread nor a mean-preserving contraction. This is similar to the reasoning in the full-default model (Doherty and Schlesinger 1990). Finally, if $t=\hat{t}$, every risk averse agent buys full coverage, whatever her degree of risk aversion. 
It is noteworthy that when $0 \leq t<\hat{t}$ more insurance increases the wealth under the insured loss state with full performance and decreases the wealth under the insured loss state with nonperformance. This contradicts the statement in Doherty and Schlesinger (1990, p.251): “A major difference from the total-default case is that more insurance increases the consumer's wealth in all loss states when $t>0$.” This statement holds only when $t>\hat{t}$.

The ambiguous relationship between the degree of risk aversion and the demand for unreliable insurance, as mentioned by Doherty and Schlesinger (1990) in the case of total default, extends to partial default, i.e., a recovery rate $0 \leq \hat{t}<1$. The approach based on mean-preserving changes in risk in the sense of Rothschild and Stiglitz (1970) is similar to that used by Briys and Schlesinger (1990) to demonstrate the ambiguous link between risk aversion and self-protection.

\section{Conclusion}

This paper has examined the demand for insurance under risk of partial default. Under the three-state model proposed by Doherty and Schlesinger (1990), an optimal fair performing insurance policy displays less-than-full (full, more-than-full) coverage as long as the recovery rate under default is lower than (equal to, higher than) a trigger rate that depends only on the probability of loss and the probability of default. Optimal less-thanfull insurance coverage under total default, as proved by Doherty and Schlesinger (1990), is thus a special case of this result. When the recovery rate is positive but less than the trigger rate, an increase in coverage decreases wealth in the worst state (loss with nonperformance) because it increases the premium more than the non-performing 
indemnity. Unreliable insurance, with a risk of partial (or total) default, does not unambiguously reduce risk. Therefore, a more risk-averse agent may have higher or lower demand for unreliable insurance than a less risk-averse agent when there is a nonnegligible risk of insurer non-performance. 


\section{References}

Briys, E. and Schlesinger, H. 1990. Risk aversion and the propensity for self-insurance and self-protection. Southern Economic Journal 57, 458-467.

Doherty, N. and Schlesinger, H. 1990. Rational insurance purchasing: consideration of contract nonperformance. Quarterly Journal of Economics 55(1), 243-253.

Hau, A. 1999. A note on insurance coverage in incomplete markets. Southern Economic Journal, 66(2), 433-41.

Mahul, O. and Wright B.D. 2004. Implications of incomplete performance for optimal insurance. Economica 71, 661-670.

Mossin, J. 1968. Aspects of rational insurance purchasing. Journal of Political Economy 76, 553-68.

Rothschild, M. and Stiglitz J.E. 1970. Increasing risk I: A definition. Journal of Economic Theory 2(3), 225-243.

Schlesinger, H., and Graf. v. d. Schulenburg, J.M. 1989. Risk aversion and the purchase of risky insurance. Journal of Economics (Zeitschrift für Nationalökonomie) 47, 309314. 
Figure 1. The trigger recovery rate as a function of the probability of loss and the probability of full performance $q$.

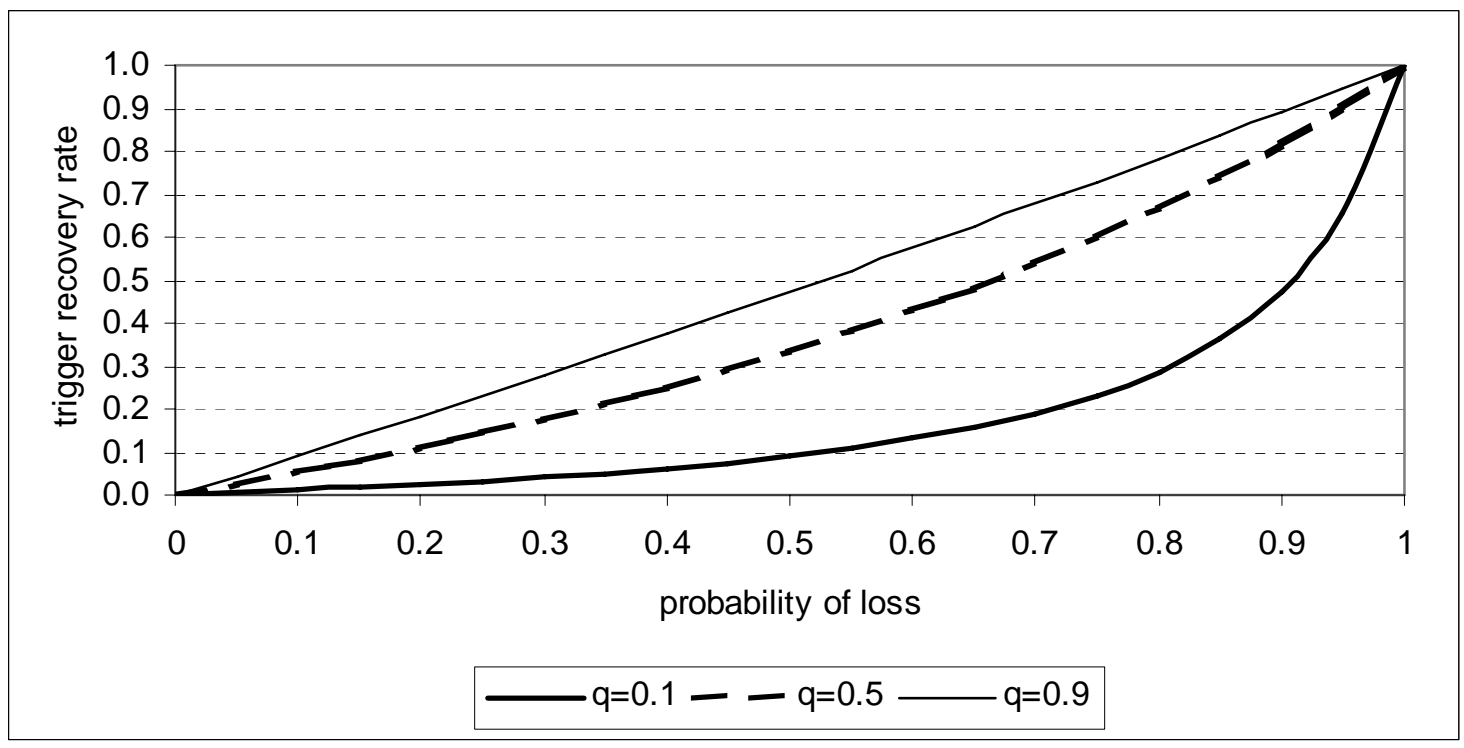

Figure 2. Impact of an increase in insurance coverage on wealth states, with $\hat{t}<t<1$.

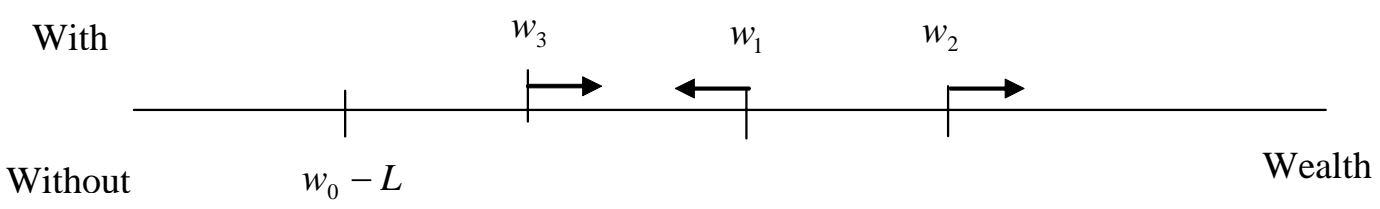

